\title{
Studies on Driftwood Motions around Obstacles by Laboratory and Numerical Experiments
}

\author{
Ichiro Kimura ${ }^{1, *}$, and Kazuya Kitazono ${ }^{2}$ \\ ${ }^{1}$ University of Toyama, Graduate School of Science and Engineering, 3190 Gofuku, Toyama 930- \\ 8555, Japan \\ ${ }^{2}$ Chubu Electric Power Co. Inc., 1 Higashi-shincho, Higashi-ku, Nagoya, Aichi 461-8680, Japan
}

\begin{abstract}
From the engineering point of view, prediction of driftwood motions around hydraulic obstacles in rivers is important. We carried out laboratory experiments to understand the driftwood behaviour around grid like obstacles and found out that there are two different patterns of the capturing process of driftwood: 2D (two-dimension) type and 3D (threedimensional) type. We proposed the governing parameter "Driftwood Richardson Number" for classifying the types of the driftwood capture. A numerical model to simulate driftwood motions based on the coupling of a Euler type three-dimensional flow model and a Lagrange type twodimensional driftwood model (3D-2D model) is proposed to analyse the driftwood behaviour around obstacles. The numerical model could predict well the flowing pattern of driftwood affected by the secondary current of the first kind in a meandering open channel. The numerical results with obstacles showed that the present $3 \mathrm{D}-2 \mathrm{D}$ type model is applicable only if the driftwood Richardson number is larger than 10, in which the driftwood capturing takes place in the $2 \mathrm{D}$ type.
\end{abstract}

\section{Introduction}

Recently, river disasters related to driftwood is increasing and becoming more serious because of various reasons, i.e., the increase of torrential rains, change of the situations of forests, increase of trees along rivers, etc. (see Figure 1). It is important to predict precisely driftwood behaviour in rivers from the standpoint of disaster prevention and environmental problems. Driftwood depositions in rivers induces various influences such as the rise in water level due to the backwater elevation, sedimentation and erosion of river bed, etc. If the density of driftwood is smaller than water, the motion of driftwood can be thought to be confined basically at the vicinity of the water surface and affected by the water flow velocity near the surface. The flow velocity near the surface is influenced by the threedimensional nature of flows such as secondary currents. In addition, driftwood deposits cause changes in the surrounding flow and affect the water level distribution due to backwater elevation.

In this study, we investigate the behaviour of driftwood motions effected by the threedimensional flow structures. We also clarify the deposition behaviour of driftwood around

\footnotetext{
* Corresponding author: ichiro@sus.u-toyama.ac.jp
} 
grid-like obstacles. We first carried out the laboratory experiments in a curved channel with and without obstacles and then tried to simulate the phenomena with a computational model. We discuss on the characteristics of phenomena through the comparison between the experimental and computational results and propose a governing parameter for the deposition pattern of driftwood around obstacles.

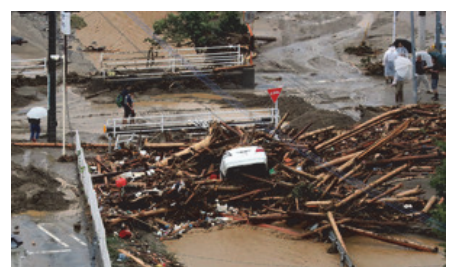

Fig.1. Example of driftwood related disaster in a river (deposition of driftwood at the upstream region of a bridge) [1].

\section{Laboratory experiments}

We used a acrylic meandering experimental flume installed in Hydraulic Laboratoy at Hokkaido University (Figure 2). The plan view of the experimental meandering flume is shown in Figure 3 . The channel width is $20 \mathrm{~cm}$, the meandering length is $3.4 \mathrm{~m}$ and the meandering angle is 60 [deg]. The shape of the meandering channel was made with a sinegenerated curve. The discharge of the flow was kept constant as $\mathrm{Q}=2.13[\mathrm{l} / \mathrm{s}]$ and the Froude number of the flow was changed by adjusting the water leverl at the channel outlet with a weir. Experiments were performed in two cases: with obstacles and without obstacles. In the case with obstacles, grid like obstacles were set at the apex region of the downstream curve as shown in Figure 1. A piece of the obstacle was made from wood pannel. It has $2 \mathrm{~cm}$ long and $1 \mathrm{~cm}$ wide rectangular cross-section. Four pieces of obstacle are set in the span-wise direction with a constant spatial interval of $3 \mathrm{~cm}$.

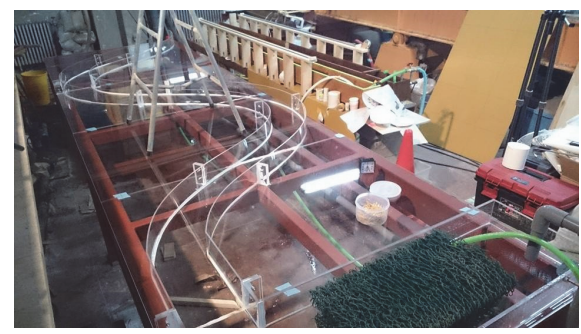

Fig. 2. A photograph of the present experimental meandering flume.

A piece of driftwood is modelled as a cylindrical shaped wood bar with $4 \mathrm{~cm}$ in the length, $5 \mathrm{~mm}$ in the diameter and $0.6 \mathrm{~g} / \mathrm{cm}^{3}$ in the density. 110 pieces of driftwood were carefully supplied to distribute equally in the spanwise direction at the upstream regions of the channel. The motion of the driftwood is recorded with a video camera. The surface flow velocity profile was analysed with PIV technique before the supply of driftwood. Water surface elevations were measured along the centreline of the channel before and after the supply of driftwood to consider the backwater elevation due to the accumulation of the driftwood behind the obstacle. 


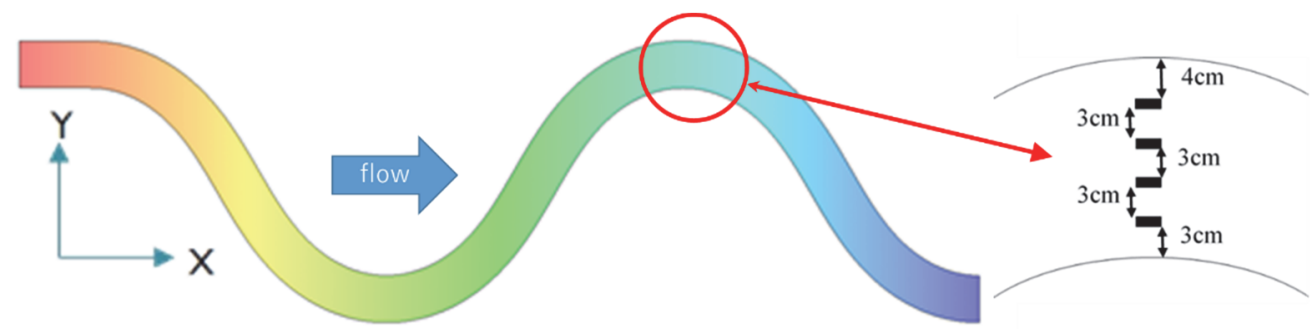

Fig. 3. Left: a plan view of the experimental meandering flume (flow is from left to right, the colour shows the bed height). Right: setting of the obstacles (each obstacle has a $2 \mathrm{~cm}$ long and $1 \mathrm{~cm}$ wide rectangular cross section.).

\section{Computational model}

\subsection{Model for water flow}

It is important to reproduce the secondary current at the channel meandering. Therefore, the computational model used in this study is based on Eulerian type fully three-dimensional Reynolds averaged Navier Stokes equations and a Reynolds averaged continuity equation. For a turbulence model, a second order non-linear k- $\varepsilon$ model is employed. The governing equations were transformed into a generalize curvilinear expressions using contra-variant components of velocity vectors, and were discretized on a staggered computational grid with a generalized curvilinear coordinate system. The TVD-MUSCL scheme was used for the inertia terms in the momentum equations and the Hybrid scheme was used for the convective terms in the $\mathrm{k}$ and $\varepsilon$ equations. The second order Adams Bashforth scheme was adopted for the time integration. The discretized momentum and continuity equations are solved in full-explicit way step by step. Number of the layers in the vertical direction is set 10. The detailed computational procedures described in the literatures $[2,3,4]$.

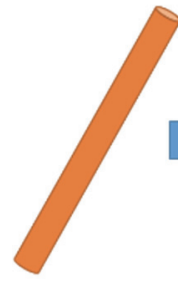

(a)

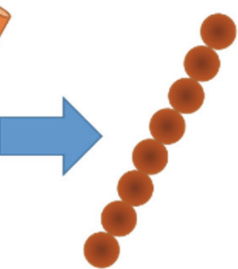

(b)

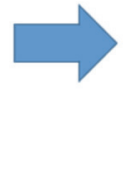

)

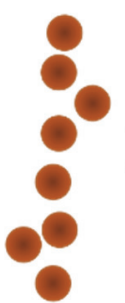

(c)

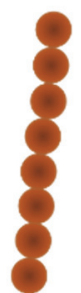

(d)

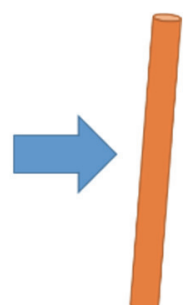

(e)

Fig.4. Schematic diagram for the model simulating driftwood motion

\subsection{Model for driftwood motion}

The motion of driftwood is assumed to be two-dimensional and to be confined at the surface layer of the flow. Driftwood is expressed as connected spheres and the collisions of driftwood is computed with DEM (Discrete Element Method). Figure 4 shows the schematic diagram of computational process for driftwood dynamics. First, a piece of driftwood is modelled as connected spheres (Fig.4. (a)-(b)). Next, each sphere is advected independently by the following Lagrange type momentum equation in a generalized curvilinear coordinate neglecting the binding force (Fig.4. (b)-(c)). 
$\frac{d U_{p}{ }^{i}}{d t}=\frac{1}{2} C_{D} \frac{A_{2}}{A_{3}} \frac{1}{d} \frac{1}{\sigma / \rho+C_{M}}\left|\mathbf{u}-\mathbf{u}_{p}\right|\left(U^{i}-U_{p}{ }^{i}\right)+\frac{1+C_{M}}{\sigma / \rho+C_{M}} \frac{d U^{i}}{d t}+\frac{1}{\sigma / \rho+C_{M}} F_{p l T}{ }^{i}$

where, $\sigma$ :density of sphere, $\rho$ : density of water, $d$ : diameter of sphere, $C_{D}:$ drag force coefficient, $U^{i}$ : contravariant component of two-dimensional velocity vector at the water surface, , $U_{p}{ }^{i}$ : contravariant component of velocity vector of sphere, $F_{p}{ }^{i}$ : contravariant component of interacting repulsion force vector between spheres, $t$ : time, $C_{M}$ : entrainment coefficient, $A_{2}, A_{3}$ : two-dimensional and three-dimensional shape coefficient, respectively $\left(A_{2}=\pi / 4, A_{3}=\pi / 6\right)$. Here, the superscript " $i$ " takes an integer value, 1 or 2 ( 1 and 2 means $\xi$ and $\eta$ directions, respectively.). After the advection of each particle, the arrangement of spheres is disturbed. Thus, the particles are rearranged again in a row (Fig.4 (d)). At this step, the gravity centre is kept identical before and after the rearrangement and the rotation angle of driftwood is determined by the average rotation angle of each particle related to the gravity centre. Repeating the procedure step by step, we can continuously track the motions of driftwood [5]. The force of collisions between driftwood is computed with DEM (Discrete Element Method).
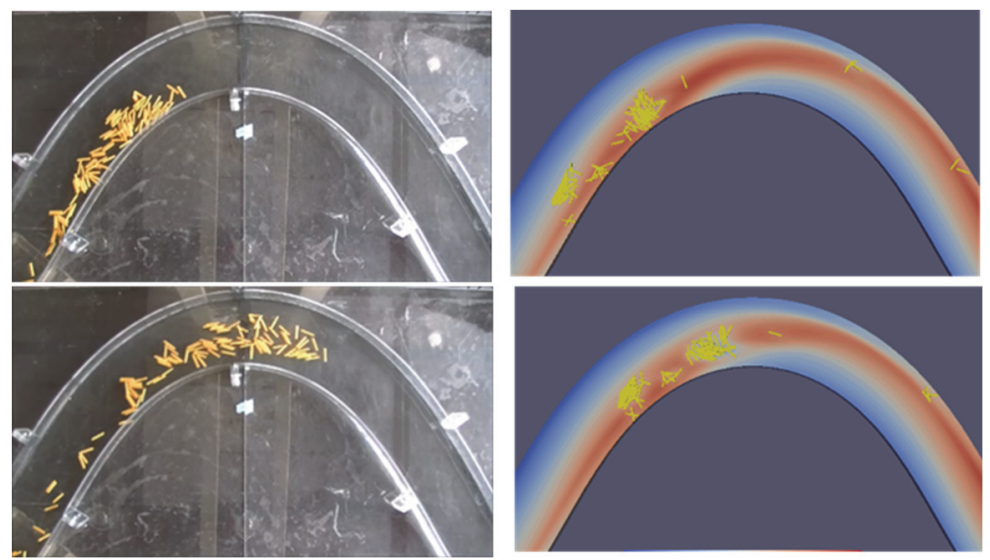

Fig.5. Computational and experimental results without obstacles. (Yellow bars show the driftwood. $\mathrm{t}=24[\mathrm{~s}]$ and 25 [s], left: experiment, right: computation).

\section{Results and discussions}

\subsection{Results without obstacle}

First, we performed the computation without obstacles to check the driftwood motions affected by the secondary current of the first kind. Figure 5 shows the comparison between the experimental and computational results in the case of no obstacles. The agreement is good. The colour contour in the numerical results shows the velocity magnitude at the surface, in which the red colour means the larger velocity portions. The result shows that the high velocity zone shifts from the inner bank toward the outer-bank along the curve. The shift is caused by the secondary flow of the first kind due to the unbalance of the centrifugal force and it can be captured only by the three-dimensional flow model. In addition, we can understand that the driftwood passes through almost the larger velocity zone. Therefore, we can understand that three-dimensional flow model is necessary to capture the driftwood motion at the curved flow region. 


\subsection{Results with obstacle and effect of Driftwood Richardson Number}

Figure 6 shows the computational result with the obstacles. The capturing the driftwood by the obstacles is clearly simulated. Generally speaking, floating motion of driftwood is confined at the region near the free surface. However, driftwood sometimes behaves threedimensionally, particularly around obstacles, where driftwood can sink against the buoyancy effect due to the advection of a downward flow. This phenomenon closely depends on the ratio of inertia force of flow and the buoyancy. To consider this effect, we introduced a new non-dimensional parameter "Driftwood Richardson Number" (Rit) for classifying the capturing processes of the driftwood by obstacles as follows:

$$
R_{i t}=\frac{g \beta\left(-\frac{1}{\rho \beta} \Delta \rho\right) h}{u^{2}}=-\frac{g}{\rho} \frac{\Delta \rho h}{u^{2}}=-\frac{g \Delta \rho B^{2} h^{3}}{\rho Q^{2}}
$$

where B: channel width, g: gravity acceleration, h: average depth, Q: discharge, $\Delta \rho$ : difference of density between driftwood and water.

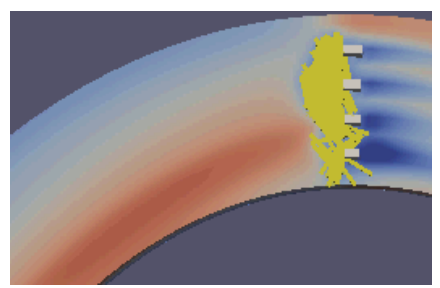

Fig.6. Computational result with obstacles. (flow direction is from left to right. The contour indicates the magnitude of velocity. Yellow bars show the driftwood.).

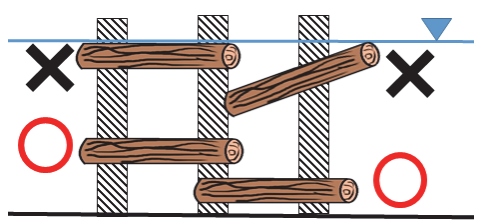

Fig.7. Definition of sunk driftwood ( $\circ$ : sunk driftwood, $\times$ : non-sunk driftwood).

The experimental reuslts showed that if the value of the driftwood Richardson number (Rit) is smaller than 10, the stack feature aound the obstacles become more threedimensional way and the accuracy by the numerical model becomes worse because the present numerical model assumes the driftwood mortion cofined in the surface layer. We define "sink rate". The sink rate is defied by the ratio of the number of sunk driftwood around the obstacle v.s. the number of all captured driftwood. Here,"sunk driftwood" is explained in Figure 7 as red circles. If whole part of the driftwood locates below the water surface, we defined it as sunk driftwood.

Figure 8 shows the relation between the driftwood Richardson number and the sink rate in the experimental results. The figure indicates that the three-dimensional behavior of the driftwood becomes rare if the driftwood Richardson number is larger than 10. Therefore, we can understand that the applicability of the present model, which couplins threedimesnional flow model and two-dimensional driftwood model, is limited in case of Rit $>$ 10. This result implys that the applicable range of the present 3D flow $-2 \mathrm{D}$ driftwood motion coupling model is Rit $>10$. 


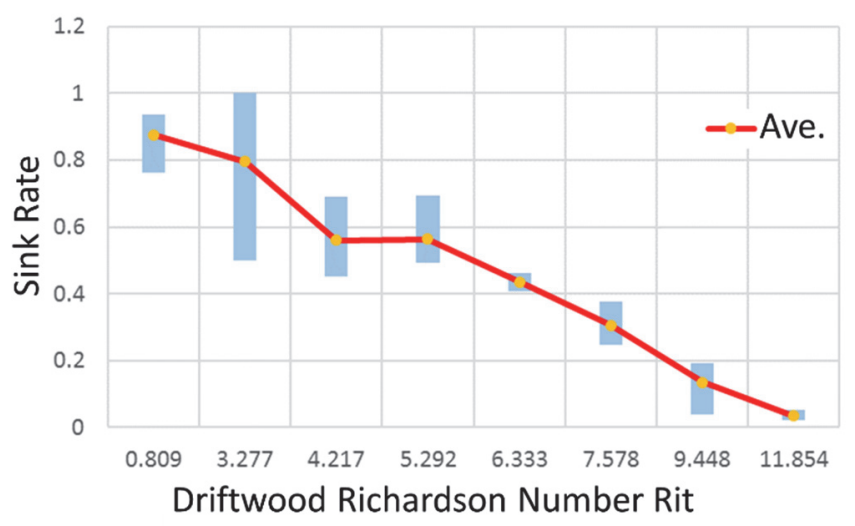

Fig.8. Relation between the driftwood Richardson Number (Rit) and the sink rate of driftwood observed in the present laboratory tests.

\section{Conclusions}

We developed a 3D flow - 2D driftwood motion coupling numerical model to analyse the motion of driftwood around obstacles in a curved open channel flow. The driftwood Richardson Number (Rit) is newly defined to consider the three-dimensional behaviour of the driftwood motion with deposition around obstacles. It is indicated that threedimensional behaviour of the driftwood becomes more dominant if the driftwood Richardson Number is smaller than 10. This feature means that the applicable range of the present 3D-2D coupling model is limited within the driftwood Richardson Number smaller than 10 .

\section{References}

1. The Asahi Shinbun newspaper (electric version), 2017.

2. Homepage of iRIC Project Changing River Science, http://i-ric.org/ja/ 2016.

3. I. Kimura, T. Hosoda. A non-linear k- $\varepsilon$ model with reliability for prediction of flows around bluff bodies. International Journal for Numerical Methods in Fluids, 813-837 (2003).

4. I. Kimura, Wim S. J. Uijttewaal, T. Hosoda and Md. Shahjahan, Ali : URANS Computations of Shallow Grid Turbulence, Journal of Hydraulic Engineering, ASCE, Vol.135, No.2, pp.118-131, (2009).

5. K. Kitazono, I. Kimura, Y. Shimizu and T. Kyuka: Computations on driftwood motions around obstacles compuling with a three-dimensionjal flow model, 20th Congress of APD IAHR, Colombo, Sri Lanka, (August 28-31, 2016), pp.1-8 (2016). 